\title{
A STUDY ON ULTRASOUND ASSISTED CANNULATION OF THE INTERNAL JUGULAR VEIN IN COMPARISON TO THE HIGH APPROACH EXTERNAL LANDMARK GUIDED TECHNIQUE
}

\author{
Sinewraz P. M1, Amjed P. A. P2
}

${ }_{1}^{1}$ Associate Professor, Department of Radiodiagnosis, Kannur Medical College, Anjarakandy, Kannur Dt. Kerala. ${ }^{2}$ Assistant Professor, Department of General Medicine, Kannur Medical College, Anjarakandy, Kannur Dt. Kerala.

\section{ABSTRACT}

\section{BACKGROUND}

Ultrasound has been a valuable tool in diagnostic and therapeutic practice in Emergency and Critical care situations. Since its first use for Central Venous access in 1978, where it was used for marking the skin site for cannulation. They have changed to real time imaging significantly decreasing the failure rate, complication rate and number of attempts required for successful access.

\section{OBJECTIVE}

To compare the ultrasound assisted cannulation of the internal jugular vein with the high approach external landmark guided technique.

\section{METHODOLOGY}

Prospective comparative study conducted in the Kannur Medical College Hospital after obtaining Institutional Ethical Committee approval. All the patients in Emergency room and Critical Care units who required internal jugular vein cannulation were included in the study.

\section{RESULTS}

Around 149 patients were taken up for the study. Among them 44 were excluded and 105 included for the study. Average access times (Skin-to-vein) were significantly reduced in the ultrasound group of patients compared with the landmark group ( $\mathrm{p}<0.001$ ). Average access time (Skin-to-vein) was 10.6 seconds ( $S D=7.68$ ) by the ultrasound approach and 48.5 seconds $(S D=33.24)$ by the landmark approach $(\mathrm{p}=0.001)$.

\section{KEYWORDS}

Ultrasound, Cannulation, High Approach External Landmark Technique and Internal Jugular Vein.

HOW TO CITE THIS ARTICLE: Sinewraz PM, Amjed PAP. A study on ultrasound assisted cannulation of the internal jugular vein in comparison to the high approach external landmark guided technique. J. Evolution Med. Dent. Sci. 2016;5(47):2964-2967, D0I: $10.14260 /$ jemds/2016/691

\section{INTRODUCTION}

Central venous cannulation is a commonly performed invasive procedure in routine and emergent situations. The importance of Central venous access in a critically ill patient cannot be stressed, with their use varying from administration of fluids and drugs, to continuous haemodynamic monitoring of the central venous pressure and therapeutically for the introduction of transvenous pacemaker. They also become the choice when there is absolutely no peripheral venous access. Many approaches have been described in standard emergency and critical care text books of gaining the access to the Internal Jugular Vein (IJV), Subclavian Vein (SV), and Femoral Vein (FV) using the traditional landmark-based approach. Among these although the subclavian has been the preferred approach because of its reliable anatomy, it has also been shown in various studies that the complication rates of pneumothorax and arterial puncture from a non-compressible site is higher compared to the internal jugular vein.

Financial or Other, Competing Interest: None.

Submission 06-02-2016, Peer Review 04-03-2016,

Acceptance 09-03-2016, Published 10-06-2016.

Corresponding Author:

Dr. Sinewraz PM,

Associate Professor,

Department of Radiodiagnosis,

Kannur Medical College,

Anjarakandy-670612

Kannur-Dist., Kerala.

E-mail: drsinuraz@gmail.com

DOI: $10.14260 /$ jemds $/ 2016 / 691$
Femoral line although easily accessible has shown increased complication with thrombosis and infection. With the relatively but importantly lesser chances of complications for an internal jugular vein, the right side is the preferred choice than the left because of its straight path, lower lying apex of pleura of the Lung and absence of the thoracic duct on the same side. However landmark-based methods have reported failure rates and complication rates as high as $30 \%$ and $18.8 \%$, respectively. ${ }^{1}$ One of the study looked at femoral venous access during Cardiopulmonary Resuscitation (CPR) and found that $31 \%$ of catheters were not in the femoral vein. ${ }^{2}$ Ultrasound has been a valuable tool in diagnostic and therapeutic practice in Emergency and Critical care situations. Since its first use for central venous access in 1978, where it was used for marking the skin site for cannulation, they have changed to real time imaging significantly decreasing the failure rate, complication rate and number of attempts required for successful access. $3,4,5$

A large randomized, multicenter trial using point-of-care limited ultrasonography assistance of central vein cannulation reported an increased success rate than the landmark approach. ${ }^{6}$ The average number of attempts and the average time to cannula placement were also significantly lower in the ultrasonographically guided group.

Although, the importance of Ultrasound in gaining a central venous access have been made mandatory in most of the western countries, to an extent that in future failure of its use will account to manslaughter, it has been very sparingly used and gaining importance lately in this part of the world 
Studies have also shown that the overall cost for the patient is actually reduced when ultrasound is used compared to the landmark approach. Combining the success and complication rates and accessibility of the vein, we intended to see how ultrasonography will aid in the cannulation of internal jugular vein.

\section{OBJECTIVE}

1. To compare ultrasound assisted cannulation of the internal jugular vein with high approach external landmark guided technique.

\section{MATERIAL AND METHODS}

This is a prospective comparative study conducted in the Kannur Medical College Hospital after obtaining Institutional Ethical Committee Approval.

All the patients in the Emergency Room and Critical Care Units, who required internal jugular vein cannulation were included in the study.

Paediatric age group, coagulation abnormality, suspected C-spine and neck injuries, previous internal jugular vein cannulation, first year resident of accident and emergency medicine were excluded.

The patients who were included in the study group were allotted for ultrasound guided internal jugular vein cannulation and control group were allotted for high approach external landmark-guided cannulation. Every alternate patient was taken for Ultrasound guided and high approach external landmark guided internal jugular vein cannulation. Comparison was done for both the groups for access time (Skin-to-vein) and its complication like pneumothorax, haemothorax, arterial bleeding, haematoma, number of attempts, thrombosis and malposition.

Written informed consent had been taken for both the groups and the procedure was explained to the patient if patient was conscious or to his relative in case the patient could not give consent.

For right internal jugular vein cannulation, the patient was positioned with rolled towel under the shoulder and head was turned to the left. The right neck had been prepared using standard sterile technique. After usual aseptic precaution site had been infiltrated with $2 \%$ lignocaine.

Following the procedure both the groups of patients were checked for their vitals, check X-ray and thoracic ultrasound was done immediately bedside. Check X-ray and thoracic ultrasound repeated whenever required. The above mentioned complications in both groups were assessed and tabulated. Finally, a comparison was drawn between both groups and statistically analysed.

\section{RESULTS}

Around 149 patients were taken up for the study. Among them 44 were excluded and 105 included for the study. After obtaining the informed consent, 52 patients were allotted to the control group and 53 were in the study group. Majority of the participants were males $(69.2 \%$ and $66 \%)$ in both the study and control groups respectively.

\section{Comparison of Complications in both the Groups}

Ventilatory support was required for both the groups during the procedure. There was no significant difference was found out. No significant difference was made out regarding the success rate in both the groups.

Average access times (Skin-to-vein) were significantly reduced in the ultrasound group of patients compared with the landmark group $(\mathrm{p}<0.001)$. Average access time (Skin-to-vein) was 10.6 seconds $(\mathrm{SD}=7.68)$ by the ultrasound approach and 48.5 seconds $(\mathrm{SD}=33.24)$ by the landmark approach $(\mathrm{p}=0.001)$.

There was a significant difference made out in the first attempt during the vein cannulation $p=0.007$. Hence, ultrasound guided internal jugular vein cannulation was easier when compared to high approach external landmark-guided cannulation. No significant difference was found out in the approaches, which was used for cannulation.

The chances of misplacing the catheter is more with high approach external landmark-guided cannulation than ultrasound-guided internal jugular vein cannulation and the difference was found to be statistically significant.

\begin{tabular}{|c|c|c|}
\hline Ventilatory Support & Study & Control \\
\hline $\begin{array}{l}\text { Yes Count\% } \\
\text { within Group }\end{array}$ & $\begin{array}{c}44 \\
84.6\end{array}$ & $\begin{array}{c}45 \\
84.9 p=0.5962\end{array}$ \\
\hline $\begin{array}{l}\text { No Count\% } \\
\text { within Group }\end{array}$ & $\begin{array}{c}8 \\
15.4\end{array}$ & $\begin{array}{c}8 \\
15.1 \\
p=0.7666\end{array}$ \\
\hline $\begin{array}{l}\text { Total Count } \% \\
\text { within Group }\end{array}$ & $\begin{array}{c}52 \\
100 \%\end{array}$ & $\begin{array}{c}53 \\
100 \%\end{array}$ \\
\hline
\end{tabular}

\begin{tabular}{|c|c|c|}
\hline Success Rate & Study & Control \\
\hline Count & 52 & 51 \\
Percentage & $100 \%$ & $96.2 \%$ \\
\hline \multicolumn{2}{|c|}{ Table 2: Comparison of Success } \\
Rate for Both the Groups \\
\hline
\end{tabular}

$\mathrm{P}=0.99$

\begin{tabular}{|c|c|c|}
\hline & Study Group & Control Group \\
\hline Mean & 10.60 & 48.52 \\
\hline Standard Deviation & 7.68 & 33.24 \\
\hline Table 3: Time Taken for Cannulation from Skin-to-Vein \\
\hline
\end{tabular}

$\mathrm{P}=0.001$

\begin{tabular}{|c|c|c|}
\hline Attempts & Study Group & Control Group \\
\hline 1st attempt & $\begin{array}{c}49 \\
94.2 \%\end{array}$ & $\begin{array}{c}39 \\
73.6 \% \\
P=0.007\end{array}$ \\
\hline 2nd attempt & $\begin{array}{c}2 \\
3.8 \%\end{array}$ & $\begin{array}{c}10 \\
18.9 \% \\
\mathrm{P}=0.45\end{array}$ \\
\hline 3rd attempt & $\begin{array}{c}1 \\
2 \%\end{array}$ & $\begin{array}{c}4 \\
7.5 \% \\
P=0.4\end{array}$ \\
\hline Total & $\begin{array}{c}52 \\
100 \%\end{array}$ & $\begin{array}{c}53 \\
100 \%\end{array}$ \\
\hline
\end{tabular}




\begin{tabular}{|c|c|c|}
\hline Approach & Study & Control \\
\hline \multirow{2}{*}{ High } & 40 & 48 \\
& $76.9 \%$ & $90.6 \% \mathrm{p}=0.9823$ \\
\hline \multirow{2}{*}{ Anterior } & 7 & 2 \\
& $13.5 \%$ & $3.8 \% \mathrm{p}=0.9722$ \\
\hline \multirow{2}{*}{ Central } & 5 & 3 \\
& $9.6 \%$ & $5.6 \% \mathrm{p}=0.2142$ \\
\hline \multirow{2}{*}{ Total } & $\mathbf{5 2}$ & $\mathbf{5 3}$ \\
& $\mathbf{1 0 0 \%}$ & $\mathbf{1 0 0 \%}$ \\
\hline \multicolumn{2}{|c|}{ Table 5: Comparison of the Groups } \\
with Different Approaches
\end{tabular}

\begin{tabular}{|c|c|c|}
\hline Arterial Puncture & Study & Control \\
\hline \multirow{2}{*}{ Yes } & 1 & 6 \\
& 1.9 & $11.3 \mathrm{P}=0.4285$ \\
\hline \multirow{2}{*}{ No } & 51 & 47 \\
& 98.1 & $88.7 \mathrm{P}=0.0525$ \\
\hline \multicolumn{3}{|c|}{ Haematoma } \\
\hline \multirow{2}{*}{ Yes } & 1 & 8 \\
& 1.9 & $15 \mathrm{P}=0.999$ \\
\hline \multirow{2}{*}{ No } & 51 & 45 \\
& 98.1 & $85 \mathrm{p}=0.2388$ \\
\hline \multirow{2}{*}{ Total } & $\mathbf{5 2}$ & $\mathbf{5 3}$ \\
& $100 \%$ & $\mathbf{1 0 0} \%$ \\
\hline \multicolumn{2}{|c|}{ Table 6: Comparison of the Groups for Arterial } \\
\hline
\end{tabular}

\begin{tabular}{|c|c|c|}
\hline Catheter Malposition & Study & Control \\
\hline \multirow{2}{*}{ Yes } & 0 & 3 \\
& 0 & $5.7 \mathrm{P}=0.001$ \\
\hline \multirow{2}{*}{ No } & 52 & 50 \\
& 100 & $94.3 \mathrm{P}=0.99$ \\
\hline \multirow{2}{*}{ Total } & 52 & 53 \\
& $100 \%$ & $100 \%$ \\
\hline \multicolumn{2}{|c|}{ Table 7: Comparison of the Groups for Catheter } \\
\hline
\end{tabular}

\section{DISCUSSION}

Average access times (Skin-to-vein) were significantly reduced in the ultrasound group of patients compared with the landmark group $(\mathrm{p}<0.001)$. Average access time (Skin-to-vein) was 10.6 seconds $(\mathrm{SD}=7.6808$ ) by the ultrasound approach and 48.5 seconds ( $\mathrm{SD}=33.24221$ ) by the landmark approach $(p=0.0001)$, present study shows significantly mean access times reduced in the ultrasound group of patients compared with the landmark group. Study done by National Yang-Ming University School of Medicine shows that average puncture (Access) times (15.8 vs. $43.7 \mathrm{~s}, \mathrm{p}<0.01) .{ }^{7}$

The vein was entered on the first attempt in $94.2 \%$ of patients using ultrasound and in $73.6 \%$ using the landmark technique $(\mathrm{p}=0.00728)$. Most of studies showing success rate of the first puncture attempt $(78-85 \%$ vs. $35-40 \%, p<0.01) .8$ The present study shows significant first attempt success rate in both study and control group. The second attempt cannulation in this study is $(3.8 \%$ vs. $18.9 \%, \mathrm{p}=0.454)$, whereas third attempt cannulation is ( $2 \%$ vs. $7.5 \%, p=0.4$ ).

The control group cannulation done with high approach $90.6 \%$ as per methodology of this study and if not able to cannulate by high approach, anterior $(3.8 \%)$ or central $(5.6 \%)$ approach is done. In study group, cannulation is done according to visualization of the vein. The $76.9 \%$ done by high approach were as $13.5 \%$ and $9.6 \%$ by anterior and central approach in study group.

Arterial puncture of the carotid artery is the most frequent complication of internal jugular vein catheterization, because of its close anatomical proximity to the internal jugular vein. The incidence of mechanical complications using the ultrasound guided technique was negligible, which is in agreement with previous reports. ${ }^{9-10}$ Yeum et $\mathrm{al}^{11}$ retrospectively analysed 150 patients who required internal jugular vein catheterization showing that arterial puncture of the common carotid artery occurred in $11.3 \%$ of the cases. In our study, carotid artery punctures were $11.3 \%$ with the landmark technique and $1.9 \%$ with the ultrasound guided technique $(\mathrm{p}=0.4285)$. Haematoma seen in $1.9 \%$ and $15 \%$ of ultrasound guided technique and landmark technique respectively ( $\mathrm{p}=0.999)$.

Catheter mal-positioning is a known complication of central venous catheterization. ${ }^{12}$ though uncommon complication of the cannulation and detected by immediate check chest X-ray or ultrasound guided placement. Central venous catheter tip placement at the junction of superior vena cava and right atrium is important for accurate central venous pressure measurement. ${ }^{13}$ In our study, 5.7\% malposition seen with landmark technique and none with ultrasound guided technique $(\mathrm{p}=0.00001)$. In a randomized controlled study authors suggest that keeping the guidewire J tip directed medially in right internal jugular vein catheterization increase correct placement of central venous cannulation towards atrium.

There is no incidence of pneumothorax and haemothorax in both studies and control group. Studies show that no cases of haemothorax and pneumothorax were observed in ultrasound guided technique, but there is incidence of pneumothorax $2.5-5 \%$ observed.14,15 In our study, no pneumothorax observed in control group due to high approach methodology. In this method, there is a rare chance of introducer needle piercing pleura due to high approach and also operators are well trained and experienced in cannulation of internal jugular vein.

Study showed that real-time ultrasound-guided catheterization of the internal jugular vein offers the advantage of a shorter access time and a reduced number of successful attempts compared with the landmark-guided technique. There is no doubt that critically ill patients benefit most from the above advantages of the ultrasound method.

\section{CONCLUSION}

The findings of this study indicate that internal jugular vein catheterization guided by real-time ultrasound results in a lower access time and a lower rate of immediate complications. This study strongly suggests that patients benefit most from the ultrasound guided technique internal jugular vein cannulation than high approach landmark technique.

\section{ACKNOWLEDGEMENT}

I express my heartfelt gratitude for her painstaking efforts in completion of the study in a better way and also to my all other teachers, colleagues in the dept. 


\section{REFERENCES}

1. Sznajder JI, Zveibil FR, Bitterman $\mathrm{H}$, et al. Central vein catheterization. Failure and complication rates by three percutaneous approaches. Arch Intern Med 1986;146(2):259-61.

2. Jastremski MS, Matthias HD, Randell PA. Femoral venous catheterization during cardiopulmonary resuscitation: a critical appraisal. J Emerg Med 1984;1(5):387-91.

3. Abboud PA, Kendall JL. Ultrasound guidance for vascular access. Emerg Med Clin North Am 2004;22(3):749-73.

4. Denys BG, Uretsky BF, Reddy PS. Ultrasound-assisted cannulation of the internal jugular vein. A prospective comparison to the external landmark-guided technique. Circulation 1993;87(5):1557-62.

5. Verghese ST, McGill WA, Patel RI, et al. Ultrasoundguided internal jugular venous cannulation in infants: a prospective comparison with the traditional palpation method. Anaesthesiology 1999;91(1):71-7.

6. Milling TJ, Rose J, Briggs WM, et al. Randomized, controlled clinical trial of point-of-care limited ultrasonography assistance of central venous cannulation: the third sonography outcomes assessment program (SOAP-3) trial. Crit Care Med 2005;33(8):17649.

7. Bing-Shi Lin, Tung-Po Huang, Gau-Jun Tang, et al. Ultrasound-guided cannulation of the internal jugular vein for dialysis vascular access in uremic patients. Nephron 1998;78:423-8.

8. Hatfield A, Bodenham A. Portable ultrasound for difficult central venous access. Br J Anaesth 1999;82(6):822-6.
9. Malloy DL, McGee WT, Shawker TH, et al. Ultrasound guidance improves the success rate of internal jugular vein cannulation: a prospective, randomized trial. Chest 1990;98:157-60.

10. Gordon AC, Saliken JC, Johns D, et al. US-guided puncture of the internal jugular vein: complications and anatomic considerations. J Vasc Interv Radiol 1998;9:333-8.

11. Hayashi H, Amano M. Does ultrasound imaging before puncture facilitate internal jugular vein cannulation? Prospective randomized comparison with landmarkguided puncture in ventilated patients. J Cardiothorac Vasc Anaesth 2002;16:572-5.

12. Sanchez R, Halck S, Walther-Larsen S, et al. Misplacement of subclavian venous catheters: importance of head position and choice of puncture site. $\mathrm{Br} \mathrm{J}$ Anaesth 1990;64:632-3.

13. Tripathi M, Dubey PK, Ambesh SP. Direction of J-tip of the guidewire, in seldinger technique, is a significant factor in misplacement of subclavian vein catheter: a randomized, controlled study. Anaesthanalg 2005;100:21-4.

14. Randolph AG, Cook DJ, Gonzales CA, et al. Ultrasound guidance for placement of central venous catheters: a meta-analysis of the literature. Crit Care Med 1996;24(12):2053-8.

15. Rao TLK, Wong AY, Salem MR. A new approach to percutaneous catheterization of the internal jugular vein. Anaesthesiology 1977;46:362-4. 